\title{
USING ACTIVATED CARBON FOR NONENZYMATIC BROWNING COMPOUNDS ADSORPTION IN PEACH PULP
}

Thamer A. Khalil

Mazin M. I. Al-Zubaidy

Department of Food Science, College of Agriculture and Forestry, Mosul

University, Iraq.

\begin{abstract}
Adsorption of dark coloured compounds onto granular activated carbon (GAC) was evaluated at different concentrations $(0.01,0.02,0.03$, and $0.04 \mathrm{~g}$ $\mathrm{GAC} / \mathrm{g}$ of peach pulp at a temperature range of $30-60{ }^{\circ} \mathrm{C}$. The adsorption equilibrium was quantified by means of adsorption isotherms in the range from 30 to $60{ }^{\circ} \mathrm{C}$. Absorbance data at $420 \mathrm{~nm}$ were used to plot all the isotherms which were best described by Langmuir isotherm model as compared to Freundlich model. Also, the efficiency of the adsorption process was studied for different GAC concentrations at different temperatures, from which it was observed that there was a notable improvement in efficiency as the GAC concentrations and temperature increased.
\end{abstract}

\section{INTRODUCTION}

Peaches are considered to be the most widely cultivated and consumed fruit crops. Processing of fruit juices may introduce some detrimental changes such as hydrolysis of carbohydrates, destruction of vitamins and amino acids, development of undesirable browning reactions, taste and odours, and the loss of volatile compounds (Gonzalez et al., 1988). Browning in juices and fruit pulps during processing and storage is of vital interest of these alterations (Toribio and Lozano, 1984), mainly due to nonenzymatic browning (NEB) processes that are caused by the Maillard reaction which takes place between carbonyl and free amino groups (Ibarz et al., 1989). Polyphenolic compounds with relatively low molecular weights have been found to be responsible for physico-chemical deterioration of some fruit juices and concentrates during storage (Constenla and Lozano, 1995; Wu et al., 1990). Further NEB not only undermines the sensorial characteristics but also causes the loss of nutrients and the formation of intermediate undesirable compounds, like furfural and 5hydroxymethylfurfural (Buedo et al., 2000). Different agents including activated carbon, gelatine/bentonite, casein, ion-exchange waxes and polyvenylpolypyrrolidone (PVPP) have been used for the removal of polyphenols from fruit juices (Giovanelli and Ravasini, 1993). Activated carbons are considered to be the best absorbent for colours and organic matters due to their excellent adsorption efficiency (El-Geundi, 1995; Hameed et al., 2008 and Landi et al., 2009). Activated carbon of high porosity and high surface area is frequently used in industry for purification and environmental remediation. Relatively, activated carbon exhibits high adsorption capacity for phenolic compounds. Several studies have been carried out to determine the equilibrium relationship of adsorption of phenolic compounds on activated carbon by using the isotherm model such as Freundlich and Langmuir (Tseng et al., 2003; 
Arslanôglu et al., 2005; Carabasa et al., 1998; Maarof et al., 2003 and Khan A. et al., 1997).

Received 12/1/2011 accepted 9/5/2011

However, studies on the adsorption of dark coloured compounds from peach pulp using activated carbon are few. The aim of this work was to focus on the adsorption behaviour of activated carbon for the dark compounds produced by browning reactions in peach pulp. This study was designed to (1) determine the adsorption isotherms at deferent temperatures by the retention onto granular activated carbon of the dark compounds in browned peach pulp, (2) obtain the Langmuir and Freundlich isotherm models to describe the adsorption processes.

Adsorption isotherms: the adsorption isotherms describe the relationships between the equilibrium concentrations of the adsorbate in the adsorbing phase (m) and the fluid phase (S) at a fixed temperature. The correlation of the isotherm data by theoretical or empirical equations is desired for practical operation.

The most common type of isotherm model is when a single adsorbate is retained in only one molecular layer. In this case the Langmuir isotherm to which many experimental data of different systems are well adjusted should be utilized:

$$
\mathrm{m} / \mathrm{m}_{0}=\mathrm{K}_{\mathrm{ads}} \mathrm{S} /\left(1+\mathrm{K}_{\mathrm{ads}} \mathrm{S}\right)
$$

where, $\mathrm{m}_{0}$ is the maximum concentration retained by the adsorbent and $\mathrm{K}_{\mathrm{ads}}$ is the Langmuir adsorption equilibrium constant, both are dependent on temperature and adsorbate-adsorbent system type.

Equation (1) can be expressed as:

$1 / \mathrm{m}$

$$
=\quad 1 / \mathrm{m}_{0}
$$$$
+
$$$$
1 / \mathrm{K}_{\mathrm{ads}} \mathrm{Sm}_{0}
$$

Another common isotherm model is Freundlich model:

$\mathrm{m}$

$$
=\quad \mathrm{k}
$$

where, $\mathrm{k}$ and $\mathrm{n}$ are adsorption parameters, also dependent on temperature and adsorbate-adsorbent system type.

Equation (3) in linear form:

$\ln$

m

$\mathrm{k}$

$1 / \mathrm{n}$

$\ln$

(4) 


\section{MATERIALS AND METHODS}

Peaches were purchased from the local market were washed, cut into 4 wedges, pitted and held in ice-water $\left(1-2{ }^{\circ} \mathrm{C}\right)$. Peach pieces were pulped in a domestic food processor to obtain the pulp. The samples of peach pulp were initially subjected to a thermal treatment of $24 \mathrm{~h}$ in an oven at $70{ }^{\circ} \mathrm{C}$. This thermal treatment produced browning reactions in the pulp that once treated, was stored in a freezer for future uses. The GAC (Riedel-De Haen Ag, SeelzeHannover, Germany) with 1.2-1.8 mm particle sizes in varying amounts of 1, 2, 3, and $4 \mathrm{~g}$ was added to flasks containing $100 \mathrm{~mL}$ of browned peach pulp. So, the concentration of GAC in the pulp ranged from 0.01 to $0.04 \mathrm{~g}$ activated carbon/g peach pulp. All flasks were then placed in a thermostated water bath at a constant temperature and samples were taken at 10, 25, 45, and $60 \mathrm{~min}$. Then the samples were filtered through a $0.25 \mu \mathrm{m}$ membrane filter prior to measurement of absorbance values at $420 \mathrm{~nm}$ and variations in the absorbance during the adsorbance process were recorded. The absorbance measurements were carried out using a Spectronic (Unicam 500 model UV spectrophotometer, England). Since the assay was done in duplicate, it was reported for different concentrations of the $\mathrm{GAC}$ at $30,40,50$, and $60{ }^{\circ} \mathrm{C}$. The initial absorbance value $\left(\mathrm{A}_{0}\right)$ of peach pulp without GAC was determined at $420 \mathrm{~nm}$. The following equation was used (Carabasa et al., 1998) to evaluate the adsorption efficiency ( $\mathrm{z} \%$ ) of the coloured compounds in the browned pulp on the GAC:

$\mathrm{Z}$ $\begin{array}{lllll}\% & = & 100\left(\mathrm{~A}_{0}\right. & - & \mathrm{A}) / \mathrm{A}_{0}\end{array}$

where, $\mathrm{A}_{0}$ is the initial absorbance at $420 \mathrm{~nm}$ and $\mathrm{A}$ is the final absorbance at $420 \mathrm{~nm}$ of peach pulp corresponding to the equilibrium time.

For the retention of coloured compounds on the GAC, the adsorption isotherm relates the amount of these compounds retained by the adsorbent $(\mathrm{m})$ to the residual absorbance of the pulp at $420 \mathrm{~nm}(\mathrm{~A})$. The $\mathrm{m}$ value can be obtained as:

$\begin{array}{llllllll}\mathrm{m} & = & \left(\begin{array}{lllll}\mathrm{A}_{0} & - & \mathrm{A}\end{array}\right) & \mathrm{C}\end{array}$

where, $\mathrm{A}$ is a measure of the coloured compounds in the pulp, and $\mathrm{C}$ is the concentration defined as $\mathrm{g}$ GAC/g peach pulp. All assays were carried out in duplicate.

Statistical analysis of the regression and goodness of fit was done using Microsoft Excel 2003 software.

\section{RESULTS AND DISCUSSION}

Figure (1) shows the effect of GAC concentrations on adsorption efficiency of dark coloured compounds contained in peach pulp samples. It can 
be noticed that the adsorption efficiency increased with increasing the GAC concentrations. This increase can be due to the increase in the number of adsorption sites (Selvaraj et al., 1997 and Sharma and Foster, 1993). Similar results were reported by Carabasa et al. (1998), Gökmen and Serpen (2002), Arslanoglu et al. (2005), and Ibars et al. (2008). On the other hand, an increase of $\mathrm{z}$ with increasing concentration of GAC can be attributed to the increase of adsorption surface. Further, it can also be noticed from Figure (1) that the adsorption efficiency tended to rise with increase in temperature. This is obvious because as the temperature rises the viscosity diminishes and the thermal motion of the pigments in the pulp is accelerated. This behavior then favoured the different adsorption stages (external transfer and diffusion within the GAC) and promoted the colored compounds to be adsorbed on the surface and inside of GAC (Carabasa et al., 1998 and Arslanôglu et al., 2005). Additionally, considering Figure (1), it is easy to see that at concentration of GAC higher than $0.02 \mathrm{~g} / \mathrm{g}$ pulp, a slight increase in the adsorption efficiency of dark coloured compounds was observed at processing temperatures $40{ }^{\circ} \mathrm{C}, 50$ ${ }^{\circ} \mathrm{C}$, and $60{ }^{\circ} \mathrm{C}$. However, no adsorption efficiency increase was observed at 30 ${ }^{\circ} \mathrm{C}$.

Figure (2) illustrates the effect of the contact time on (z \%) of dark coloured

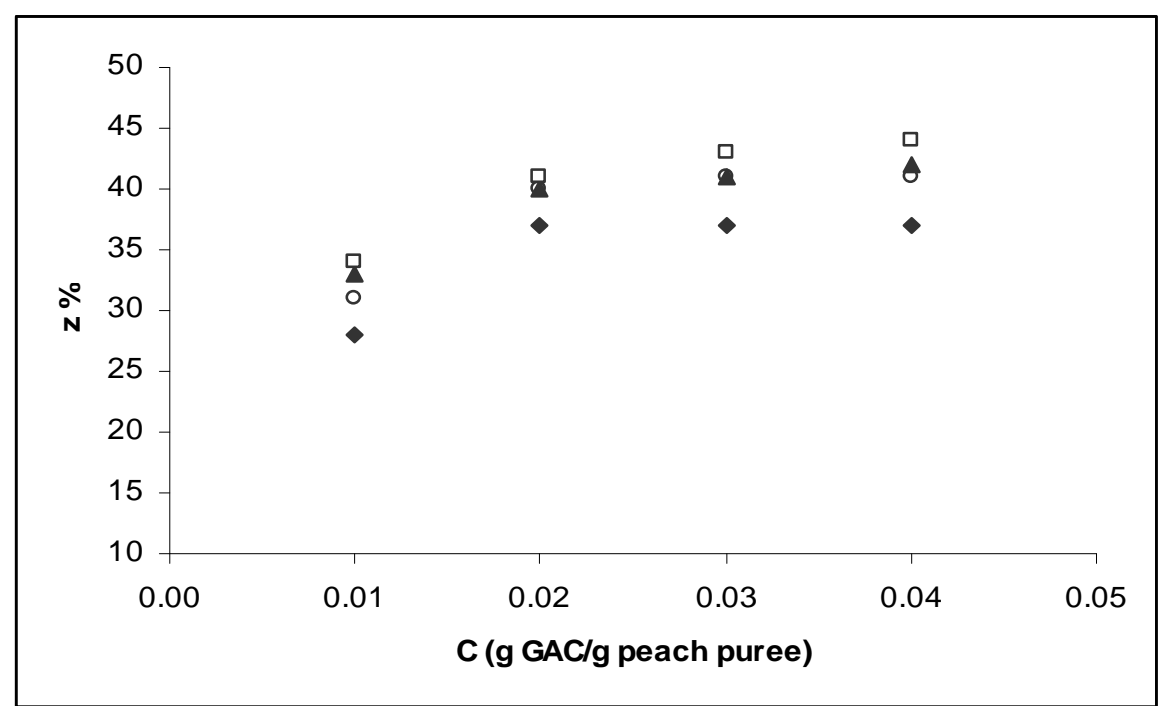

Figure (1). Evolution of adsorption efficiency (z) with GAC/peach pulp ratios at different temperatures: $(\diamond) 30{ }^{\circ} \mathrm{C}$; (०) $40{ }^{\circ} \mathrm{C}$; (4) $50{ }^{\circ} \mathrm{C}$; ( $\square) 60{ }^{\circ} \mathrm{C}$.

compounds in the peach pulp using GAC. The $\mathrm{z}$ values were increased with increasing contact time. Initially the adsorption efficiency at 45 min contact time is relatively high at all studied temperatures and the equilibrium is attained at $45 \mathrm{~min}$. More than half of the total $\mathrm{z} \%$ change corresponding to one hour adsorption was reached at $10 \mathrm{~min}$. These results indicate that the adsorption process is tending to be quite fast. So that it can be considered that the GACpeach pulp contact time of $45 \mathrm{~min}$ at temperature $30-60{ }^{\circ} \mathrm{C}$ is a suitable 
treatment to improve the colourimetric characteristics of peach pulp and restore it to its normal colour. Longer contact times unnecessarily prolong the process to obtain similar results.

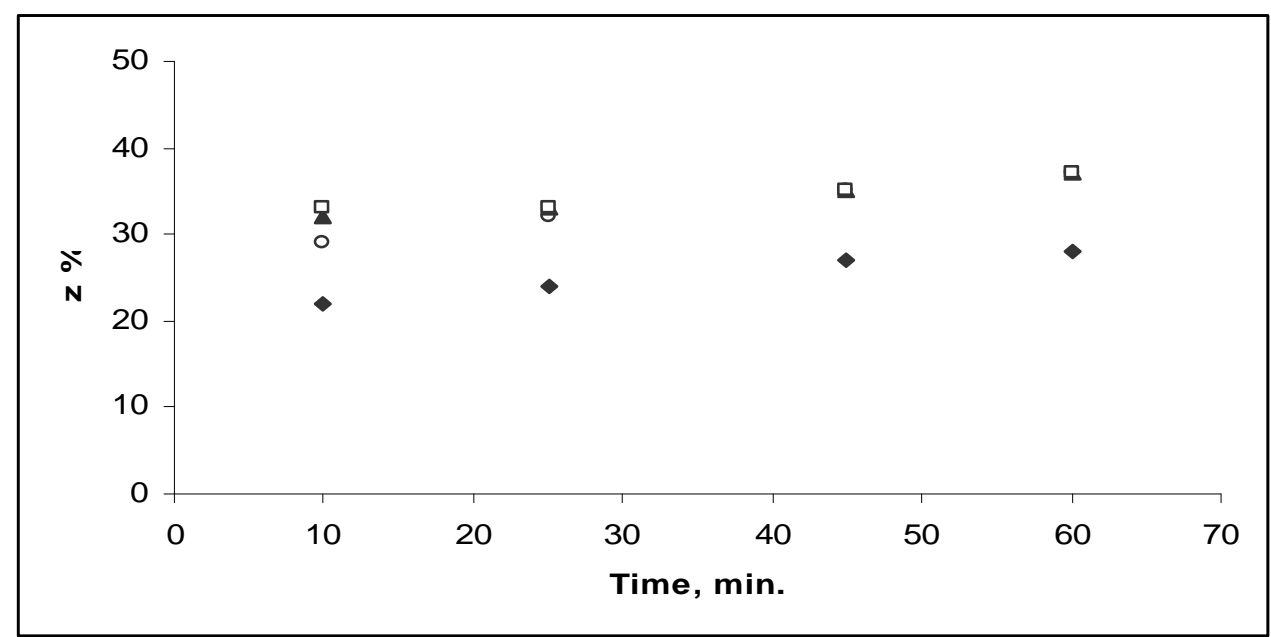

Figure (2): Effect of contact time on the adsorption efficiency of dark coloured compounds by $0.02 \mathrm{~g} \mathrm{GAC} / \mathrm{g}$ peach pulp at $(\diamond) 30^{\circ} \mathrm{C},(\mathrm{\circ})$ $40{ }^{\circ} \mathrm{C},(\Delta) 50{ }^{\circ} \mathrm{C},(\square) 60{ }^{\circ} \mathrm{C}$.

Adsorption isotherms: The equilibrium data was correlated with the Langmuir and Freundlich models which are the most commonly isotherms used in the case of monocomponent systems if the solute is retained in only one molecular layer. Concerning the Langmuir equilibrium isotherm, the fittings to Equation (2) with the adsorption equilibrium constant $\left(\mathrm{K}_{\mathrm{ads}}\right)$ and maximum adsorption capacity $\left(\mathrm{m}_{0}\right)$ determined from the slope and intercept of the plot of $1 / \mathrm{m}$ against $1 / \mathrm{S}$, respectively. For the Freundlich model, and when Equation (4) was performed, the parameters $\mathrm{k}$ and $1 / \mathrm{n}$ were determined from the intercept and the slope of the plot $\ln \mathrm{m}$ versus $\ln \mathrm{S}$, respectively Table (1).

Table (1): Parameters for Langmuir and Freundlich isotherms

\begin{tabular}{|c|c|c|c|c|c|c|}
\hline \multirow{2}{*}{$\begin{array}{c}\text { Temperatur } \\
\mathrm{e}\left({ }^{\circ} \mathrm{C}\right)\end{array}$} & \multicolumn{2}{|c|}{ Langmuir parameters } & \multicolumn{3}{|c|}{ Freundlich parameters } \\
\cline { 2 - 7 } & $\mathrm{m}_{0}$ & $\mathrm{~K}_{\mathrm{ads}}$ & $\mathrm{R}^{2}$ & $\mathrm{k}$ & $\mathrm{n}$ & $\mathrm{R}^{2}$ \\
\hline 30 & 17.12 & 0.51 & 0.9907 & 19.21 & 0.84 & 0.9762 \\
\hline 40 & 18.80 & 0.43 & 0.9927 & 22.73 & 0.74 & 0.9695 \\
\hline 50 & 22.56 & 0.29 & 0.9994 & 25.87 & 0.71 & 0.9756 \\
\hline 60 & 24.28 & 0.21 & 0.9986 & 29.04 & 0.68 & 0.9903 \\
\hline
\end{tabular}

It could be observed by comparing the correlation coefficient values, $\mathrm{R}^{2}$ of the linear plots, that the adsorption equilibrium data of dark compounds was best described by Langmuir isotherm model as compared to Freundlich model. It is shown that for the Langmuir model and under the conditions studied the adsorption equilibrium constant $\left(\mathrm{K}_{\mathrm{ads}}\right)$ decreased with the increase in temperature, so the desorption stage became greater with increased temperature. Conversely, $\mathrm{m}_{0}$ (maximum amount of solute adsorbed per unit 
weight of adsorbent) increased with increasing temperature. The increase in $\mathrm{m}_{0}$ at a higher temperature may be related to the increase in the movement of the colored compound, and thus, led to an increase the mass transfer (Ibarz et al., 2008). For the Freundlich parameters, the $(\mathrm{k})$ constant which represents the carbon adsorption capacity when the peach pulp has a given residual absorbance, increases with increasing temperature. However, the value of (n) (Freundlich constant) appears to decrease with increasing temperature. The last observations agreed with the work done by Carabasa et al. (1998) and Arslanôglu et al. (2005). The Freundlich expression is an exponential equation and therefore it assumes that, as the adsorbate concentration increases, the concentration of adsorbate on the adsorbent surface also increases (Arslanôglu et al., 2005 and Lucio et al., 2008).

In conclusion, it was shown that the adsorption efficiency of dark coloured compounds increased with increasing granular activated carbon dosage and temperature. Taking into account the different process variables in an adsorption process, a carbon-pulp contact time of 45 min with a temperature from 30 to $60^{\circ} \mathrm{C}$ is enough to improve the colour of peach pulp and drive it to normal colour. Longer contact times unnecessarily prolong the process to obtain similar results. The adsorption equilibrium data of dark compounds was best described by Langmuir isotherm model as compared to Freundlich model.

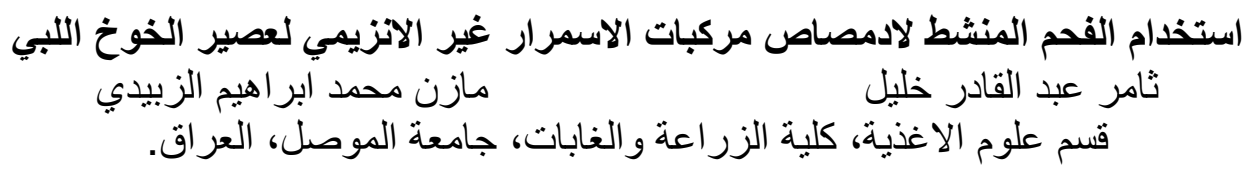

الخلاصة

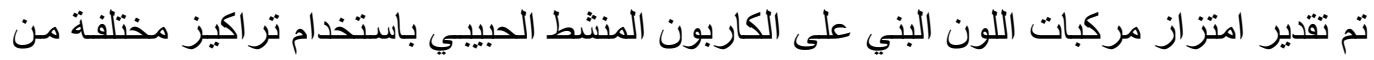

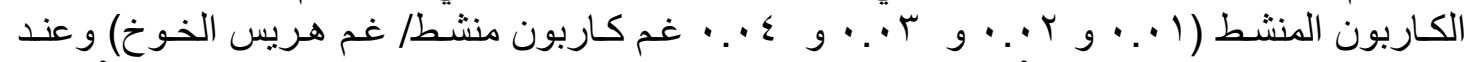

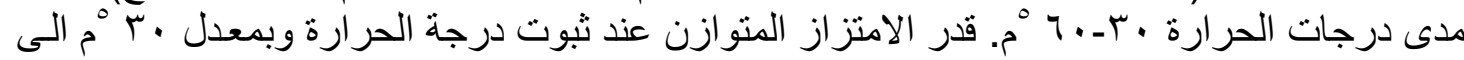

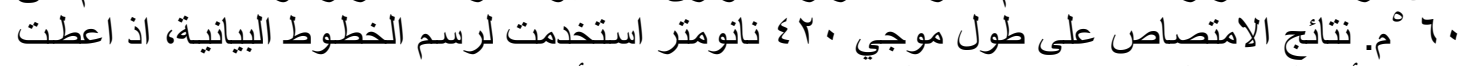

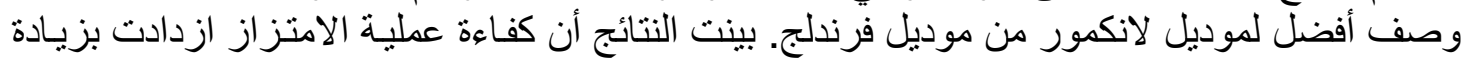
التركيز المضاف من الكاربون المنشط الحبيبي وبارتفاع درجة فئ الحرارة.

\section{REFERENCES}

Arslanôglu, F.N.; F. Kar and N. Arslan (2005). Adsorption of dark coloured compounds from peach pulp by using granular activated carbon. Jour. Food Eng. 68: 409-416.

Buedo, A.P.; M.P. Elustondo and M.J. Urbicain (2000). Nonenzymatic browning of peach juice concentrate during storage. In Nutritionists meet Food Scientists and Technologists (2000) Conference, Porto, Portugal.

Carabasa, M.; A. Ibarz; S. Garza and G. V. Barbosa-Ca' novas (1998). Removal of dark compounds from clarified fruit juices by adsorption processes. J. Food Eng. 37: 25-41. 
Constenla, D.T. and J.E. Lozano (1995). Effect of ultrafiltration on concentrated apple juice colour and turbidity. Int. Jour. Food Sci. and Technol., 30, 23-30.

El-Geundi, M.S. (1995). Adsorbents for industrial pollution control. Adsorption Sci. Technolo., 51: 37-42.

Giovanelli, G. and G. Ravasini (1993). Apple juice stabilization by combined enzyme-membrane filtration process. Lebensmittel-Wissenschaft undTechnologie, 26: 1-7.

Gökmen, V. and A. Serpen (2002). Equilibrium and kinetic studies on the adsorption of dark colored compounds from apple juice using adsorbent resin. Jour. Food Eng., 53: 221-227.

Gonzalez, C.; A. Ibarz; S. Esplugas and M. Vicente (1988). Cinetica de1 pardeamiento no enzimatico de zumos de frutas. Alimentaria, 198: 53-60.

Hameed, B.H.; I.A.W. Tan and A.L. Ahmad (2008). Adsorption isotherm, kinetic modeling and mechanisms of 2, 4, 6-trichlorophenol on coconut husk-based activated carbon. Chem. Eng. Jour. 144: 235-244.

Ibarz, A.; T. Casero; R. Miguelsanz and Jour. Pagan (1989). Cinetica de pardeamiento no enzimatico de concentrado de zumo de pera almacenado a distintas temperaturas. Rev\&u de Agroquimica y Tecnologia de Alimentos, 29(3): 407-414.

Ibarz, A.; S. Garza; A. Garvin and Jour. Pagan (2008). Kinetics of peach clarified juice discoloration process with an adsorbent resin. Food Sci. Technolo. Int. 14: 57-62.

Khan, A.R.; T.A. Al-Bahri and A. Al-Haddad (1997). Adsorption of phenol based organic pollutants on activated carbon from multi-component dilute aqueous solutions. Water Research, 31: 2102-2112.

Landi, M.; V. Naddeo and V. Belgiorno (2009). Phenol removal by adsorption on activated carbon enhanced with ultrasound. Proceedings of the $11^{\text {th }}$ International Conference on Environmental Science and Technology, Chania, Crete, Greece, 3-5 September 2009.

Lucio, D.; D. Laurent and G. Roger (2008). Adsorption of remazol black B dye on activated carbon felt. Carbon-Science Technolo. 1/2: 66-71.

Maarof, H.I.; B.H. Hameed and A. L. Ahmad (2003). Adsorption isotherm of O-cresol from Aqueous solution by granular activated carbon. Proceedings of International Conference On Chemical and Bioprocess Engineering $21^{\text {th }}-29^{\text {th }}$ August 2003 . Universiti Malaysia Sabah. Kola Kinabalu

Selvaraj, K.; V. Chandramohan and S. Pattabhi (1997). Removal of $\mathrm{Cr}(\mathrm{VI})$ from solution and chromium plating industry wastewater using photofilm waste sludge. Indian Jour. Chem. Technolo., 18: 641-646.

Sharma, D.C. and C.F. Foster (1993). Removal of hexavalent chromium using sphagnum moss peat. Water Research, 27: 1201-1208.

Toribio, J.F.; J.E. Lozano (1984). Nonenzymatic browning in apple juice concentrate during storage. Jour. Food Sci., 49: 889-892. 
Tseng, R.L.; F.C. Wu and R.S. Juang (2003). Liquid-phase Adsorption of Dyes and Phenols using Pinewood-based Activated Carbons. Carbon, 41: 487-495.

Wu, M.L.; R.R. Zall and W.C. Tzeng (1990). Microfiltration and ultrafiltration comparison for apple juice clarification. Jour. Food Sci., 55: 1162-1163. 